Article

\title{
An Empirical Study on Dynamic Evolution of Industrial Structure and Green Economic Growth-Based on Data from China's Underdeveloped Areas
}

\author{
Gefu Liang ${ }^{1}$, Dajia Yu ${ }^{1, *}$ and Lifei Ke ${ }^{2}$ \\ 1 School of Business, Guangxi University, Nanning 530004, China; liang630@gxu.edu.cn \\ 2 Department of Airport Economics, Beijing Institute of Economic and Management, Beijing 100102, China; \\ lifeike@beim.edu.cn \\ * Correspondence: yudajia@gx.chinamobile.com; Tel.: +86-139-7719-8800
}

Citation: Liang, G.; Yu, D.; Ke, L. An Empirical Study on Dynamic

Evolution of Industrial Structure and Green Economic Growth-Based on Data from China's Underdeveloped Areas. Sustainability 2021, 13, 8154. https://doi.org/10.3390/su13158154

Academic Editor: Bazyli Czyżewski

Received: 3 June 2021

Accepted: 19 July 2021

Published: 21 July 2021

Publisher's Note: MDPI stays neutral with regard to jurisdictional claims in published maps and institutional affiliations.

Copyright: (C) 2021 by the authors. Licensee MDPI, Basel, Switzerland. This article is an open access article distributed under the terms and conditions of the Creative Commons Attribution (CC BY) license (https:// creativecommons.org/licenses/by/ $4.0 /)$.

\begin{abstract}
From the experiences of developed countries or areas, advanced industrial structure is an effective way to promote economic transformation and high-quality growth. This paper uses the economic development data of seven underdeveloped provinces in China in 10 years to study the relationship between industrial structure upgrading, industrial structure rationalization and green economic growth. The result shows: (1) The relationship between the upgrading of industrial structure and green total factor productivity (GTFP) is a non-linear relationship that is difficult to fit. (2) There are two turning points in the relationship curve between industrial structure upgrading and green total factor productivity (these can be called "rationalization points"). (3) The "rationalization points" are affected by the rationalization of the industrial structure. (4) The "rationalization point" divides the relationship curve into three intervals. Within the threshold range [0.661, 0.673] of the rationalization of the industrial structure, the upgrading of the industrial structure promotes the increase of green total factor productivity, while outside the range, the upgrading of the industrial structure inhibits the increase of green total factor productivity. Therefore, industrial development in underdeveloped areas should first implement rationalization of industrial structure. After the rational adjustment of the industrial structure, we will then develop a high-level industrial structure to improve the green TFP.
\end{abstract}

Keywords: green economic growth; green total factor productivity; industrial structure upgrading; threshold effect model

\section{Introduction and Literature Review}

Since the 1980s, China's rapid economic growth is driven by structural changes in the economy. In the past 40 years, among the three industries, the proportion of agriculture in China is declining, while industry and services are growing steadily, even become an important driving force for China's economic development. This series of economic structural adjustments marks China's industrial structure upgrading. However, the environmental problems produced by the economic development of developed countries in the past hundred years also emerged in the process of China's economic development in recent decades. The developed areas of China have basically completed the transformation of industrial structure, but with the development of industrialization and urbanization, as well as the transfer of high-polluting industries in some developed regions, the pressure on the environment in less-developed regions is further increasing. According to World Bank data for 2019, the economic loss caused by air pollution is equivalent to $10 \%$ of China's GDP. The traditional extensive model of economic development can no longer facilitate the sustained development of China's economy. Tighter resource constraints and serious environmental pollution have become major obstacles to high-quality economic development in China. Industrial structure is an important link to resource environment 
and economic growth. Under the constraints of resources and environment, how to achieve resource conservation, environmental improvement, and efficiency improvement through industrial structure optimization while maintaining economic growth is an important topic for underdeveloped areas to realize green growth transformation and rural revitalization.

The most important task for China's economic development at present is to transform the development model, adjust the economic structure, and find new drivers of growth. Due to the limitation of resources and environment, underdeveloped areas should not and cannot directly learn from the economic development experience of developed areas [1,2].

Green economic growth means, on the basis of minimizing environmental damage and loss of natural resources, increasing the level of input and output and promoting coordination of economy sustainable development, society, and ecology. This paper defines the adjustment of industrial structure from two angles of upgrading and rationalization. Advanced industrial structure refers to the process of developing industrial structure to high efficiency, which was first proposed by Japanese economic economists. After 1955, in order to realize the rapid development of the Japanese economy, economists and the government put forward "industrial structure upgrading" as "national industrial structure policy". The upgrading of industrial structure is based on the perspective of vertical change, that is, the transformation process of industrial structure from low level to high level. The evolution of industrial structure towards a higher level of internal comprehensive productivity and technological structure is mainly manifested in the development of high-tech industries. Industrial structure rationalization is based on the perspective of horizontal change, which is a process of realizing the balance between industries, between technology and resources, between demand and supply, and finally realizing the coordinated development of industrial scale, industrial correlation, and economic growth. Industrial structure rationalization emphasizes the reasonable allocation of production factors and raises the utilization rate of production factors, then produces good economic benefits.

The acceleration of industrial structure optimization usually occurs in the postindustrial development stage [3-5]. When the regional economy develops to a higher stage, the development of the secondary industry will provide a good foundation for the development of the tertiary industry. In other words, the development of the secondary industry provides factor transfer and technical support for the service industry and drives the development of the supporting service industry [6,7]. Underdeveloped areas are often in the primary stage of industrialization, and the contradiction among economic growth, industrial structure, and environmental protection still exists [8-10]. If underdeveloped areas shift the focus of resources to the tertiary industry, the proportion of the tertiary industry will artificially increase, and the limited development of agriculture and industry will hardly support the development of the service industry [11]. This kind of industrial policy that violates the law of the market may lead to an imbalance in industrial structure, thus deepening the contradiction among green economic growth, rational industrial structure, and advanced industrial structure. That is, how to balance the upgrading of industrial structure and the rationalization of industrial structure, and how to choose and formulate appropriate industrial policies are the important issues facing the economic growth of underdeveloped areas.

Regarding the relationship between industrial structure and economic development, many researchers all around the world have conducted beneficial research and exploration. Many economists emphasized the importance of industrial structure in economic growth in the theory of industrial growth [12-14]. The traditional school of industrial structure, represented by the Petti-Clark theorem, holds that industrial structure adjustment can bring "structural dividend" [15]. For example, economic development promotes industrial structure evolution through the development of leading industries from the low level to the high level $[16,17]$. We should first realize the replacement and growth of primary, secondary, and tertiary industries in turn; promote the production factors which flow from low-productivity sectors to high-productivity sectors; and give priority to development of the high-productivity sectors so as to promote rapid economic growth [18-20]. The 
improvement of productivity is a significant reason for economic growth [21,22]. The theory of the "structural dividend hypothesis" indicates that the optimization of industrial structure can promote the flow of production factors to industrial sectors with high productivity, and the resulting "structural dividend" enhances the whole social productivity level and promotes economic sustainable development [23]. Chinese scholars also put forward similar viewpoints. Cai Fang has studied China's economic development since the reform and opening-up and indicates that the improvement of China's TFP mainly comes from the "structural dividend" brought by the transfer of the labor force from agriculture to non-agricultural industries [24]. Underdeveloped countries have the advantage of being a back mover in their rapid economic growth, which allows them to realize industrial replacement and enhancement $[25,26]$.

Some scholars have affirmed the positive role of industrial structure upgrading through studies of many countries [27]. However, an increasing number of studies are putting forward a completely different point of view from the traditional industrial structure theory. Some scholars have conducted empirical tests. Fagerberg studied the industrial development process in 39 countries and areas around the world, he found that industrial structure and TFP have a negative relationship [28]. Sinhg. L studied the factors influencing the development of South Korea's manufacturing industry from 1970 to 2000 and proposed that there is a non-linear relationship between the transformation of industrial structure and the improvement of productivity. In the 1970s, there was a positive relationship between the transformation of industrial structure and the improvement of productivity, but since then the positive driving effect has not been obvious [29].

To sum up, there are many useful studies on the industrial structure adjustment and economic growth, but these studies focus more on whether industrial structure adjustment brings "structural dividend", which often ignored the requirements of green development. In particular, when the economic growth of underdeveloped areas is targeting the coordination of "quality" and "speed", the existing studies have not been able to provide proof of the relationship between industrial structure upgrading and green TFP. In other words, for China's economy, facing ecological constraints, the formulation and implementation of industrial policies in underdeveloped areas lack the support of empirical data through the study on the dynamic relationship between industrial structure and green TFP. This paper will provide a reasonable path reference for the adjustment of industrial structure for areas in different stages of economic development and resource endowment conditions.

\section{Theoretical Analysis and Hypothesis}

The relationship between industrial structure upgrading and green economy development in underdeveloped areas is not necessarily linear, and underdeveloped areas should not directly learn from the experience of green economic development in developed areas. China has made some progress in green economic growth; however, in terms of spatial distribution, there is a big gap between regions. The eastern region has achieved rapid economic growth and the transformation and optimization of industrial structure, while the less developed regions are faced with resource and environmental constraints [30-34]. Economies of scale in the manufacturing industry may lead to an increase in energy consumption and the emission of various pollutants, leading to environmental deterioration and a decline in the growth level of green economy [35-39]. At this stage, there may be a negative relationship between the high-level industrial structure and the growth of green economy. When a region's dominant industry shifts from primary to secondary, it is likely to lower the level of green economic growth. The increase in the proportion of the tertiary industry will help to improve the efficiency of resource utilization and increase the green TFP [40-42]; thus, the relationship between high-level industrial structure and green economic growth is likely to turn into a positive relationship. When the relationship between industrial structure upgrading and green economic growth is in a positive phase, the upgrading of secondary and tertiary industrial structures will enhance the level of green economic growth. At this time, green growth will support the development of green 
industries, jobs, and technologies, with the overall goal of green economic development being to reduce climate change and biodiversity loss, and to ensure access to clean water and energy. In terms of the key aspects of economic performance, it can also achieve poverty reduction, job creation, social responsibility, and improved environmental performance.

This paper makes green total factor productivity as the proxy variable of green economic growth. Because the utilization efficiency of production factors affects the green total factor productivity of ascension, and the rationalization of industrial structure indexes is characterization of the utilization efficiency of factors of production and the degree of coordination between different industries, green total factor productivity will be affected by the rationalization. Therefore, the following hypothesis is proposed: The relationship between industrial structure upgrading and green total factor productivity in underdeveloped areas is non-linear. When the leading industry shifts from the primary industry to the secondary industry economy, or even the tertiary industry economy, the growth level of green economy may decline for the first time and then rise. In other words, there is a U-shaped curve between the upgrading of industrial structure and the growth of green economy, and the influence of the rationalization of industrial structure is the reason for the inflection point of the U-shaped curve.

\section{Sample Selection and Data Sources}

This paper examined data from 2000 to 2019. Based on data availability, Guizhou, Gansu, Yunnan, Inner Mongolia, Shaanxi, Sichuan, and Guangxi were selected. These provinces have the largest number of state-level poverty-stricken counties in China. The common features of the seven provinces are as follows: (1) they have a relatively large number of state-level poverty-stricken counties. (2) They belong to ethnic minority-gathering areas. (3) There are large areas of remote mountainous area. They are faced with problems such as a shortage of natural resources, environmental deterioration, and relatively backward economic development.

The data sources were as follows: the China statistical yearbook, the China statistical yearbook of science and technology, the provinces statistical yearbook, the China environment yearbook, the CSMAR database, and the Wind database.

\section{Measures of Green Total Factor Productivity}

\subsection{Method Introduction}

In this paper, the Malmquist Luenberger productivity index, which can deal with undesired output, the looseness of input-output variables, and the non-radial and nonangular productivity index, are selected for research to build a both "undesired output" and "desirable output" production possibility set (DEA-Global-Malmquist model).

Each province is taken as an independent decision unit, and a decision unit is assumed $\mathrm{DMU}_{\mathrm{i}}(\mathrm{i}=1.2, \ldots, \mathrm{I})$; each decision unit uses $\mathrm{N}$ kinds of resource inputs $\mathrm{x}=\left(\mathrm{x}_{1}, \ldots, \mathrm{x}_{\mathrm{N}}\right) \in$ $R_{N}^{+}$to produce $M$ kinds of "desirable output", $Y_{m}=\left(y_{1}, \ldots, y_{m}\right) \in R_{M}^{+}$and emits $j$ kinds of "undesired outputs"(pollutants) $B j=\left(b_{1}, \ldots, j \in R_{I}^{+} T\right.$. $(x, y, b)$ describes the input-output of a decision unit. The production possibility set is constructed as: $\mathrm{P}(\mathrm{x})=$ $\{(\mathrm{y}, \mathrm{b}): \mathrm{x}$ can produce $(\mathrm{y}, \mathrm{b})\}, \mathrm{x} \in \mathrm{R}_{\mathrm{N}}^{+}$.

Assuming that returns to scale are constant, $\mathrm{P}(\mathrm{x})$ satisfies the following assumptions: (1) a bounded closed set and a convex set. (2) "Desirable output" and inputs are strongly manageable: if $x_{1} \geq x_{2}$, then $\mathrm{P}\left(\mathrm{x}_{1}\right) \in \mathrm{P}\left(\mathrm{x}_{2}\right)$. If $\left(\mathrm{y}_{1}, \mathrm{~b}\right) \in \mathrm{P}(\mathrm{x})$ and $\mathrm{y}_{1} \geq \mathrm{y}_{2}$, then $\left(\mathrm{y}_{1}, \mathrm{~b}\right) \in$ $\mathrm{P}(\mathrm{x})$. Under the condition of a certain input, the "desirable output" reduction is technically achievable. (3) "Undesired outputs" are joint weak disposability: if $(y, b) \in P(x)$ and $0 \leq \theta \leq 1$, then $\left(\theta_{\mathrm{y}}, \theta_{\mathrm{b}}\right) \in \mathrm{P}(\mathrm{x})$. The hypothesis suggests that in manufacturing feasibility, which is often accompanied with a "desirable output" and "undesirable output", in order to reduce "undesirable output", you must reduce "desirable output". It indicates that in the production process or in economic activity, the "undesirable output" inevitably damages the "desirable output" of production, reducing the pollutant emissions and at the same time bringing the expectation output of GDP to decrease. (4) The Theorem of 
Zero Combination: if $(y, b) \in P(x)$ and $b=0$, then $y=0$. This hypothesis means that only on the premise that the "desirable output" is 0 , the "undesirable output" can be 0 , that is, the "desirable output" and "undesirable output" are closely related. If there is "desirable output", "undesirable output" will inevitably be generated. If the production process conforms to the zero-binding theorem, it means that the production will inevitably produce pollution emissions.

Supposing that in each period $t=1, \ldots, T$, the inputs and outputs of the $k=1, \ldots, K$ region are $\left(\mathrm{x}^{\mathrm{k}, \mathrm{t}}, \mathrm{y}^{\mathrm{k}, \mathrm{t}}, \mathrm{b}^{\mathrm{k}, \mathrm{t}}\right)$, and there are $\mathrm{n}=1, \ldots, \mathrm{N}$ input elements, $\mathrm{m}=1, \ldots, \mathrm{M}$ "desirable output" and $i=1, \ldots, \mathrm{I}$ "undesirable output". DEA can be used to construct an environmental technology set that can meet the above properties:

$\mathrm{P}^{\mathrm{t}}\left(\mathrm{x}^{\mathrm{t}}\right)=\left\{\left(\mathrm{y}^{\mathrm{t}}, \mathrm{b}^{\mathrm{t}}\right) \sum_{\mathrm{k}=1}^{\mathrm{K}} \mathrm{z}_{\mathrm{k}}{ }^{\mathrm{t}} \mathrm{y}_{\mathrm{km}}{ }^{{ }^{3}} \mathrm{y}_{\mathrm{m}}{ }^{\mathrm{t}}, \mathrm{m}=1, \ldots, \mathrm{M} ; \sum_{\mathrm{k}=1}^{\mathrm{K}} \mathrm{z}_{\mathrm{k}}{ }^{\mathrm{t}} \mathrm{b}_{\mathrm{ki}}{ }^{\mathrm{t}}=\mathrm{b}_{\mathrm{i}}{ }^{\mathrm{t}}, \mathrm{i}=1, \ldots, \mathrm{I} ; \sum_{\mathrm{k}=1}^{\mathrm{K}} \mathrm{z}_{\mathrm{k}}{ }^{\mathrm{t}} \mathrm{x}_{\mathrm{kn}}{ }^{\mathrm{t}} \mathcal{L}_{\mathrm{n}}{ }^{\mathrm{t}}, \mathrm{n}=1, \ldots, \mathrm{N} ; \mathrm{z}_{\mathrm{k}}{ }^{\mathrm{t}} \geq 0, \mathrm{k}=1, \ldots, \mathrm{K}\right\}$

In this model (1), $z_{k}{ }^{t}$ represents the weight of each cross-section observation value, and the non-negative weight variable represents that the return to scale of production technology is constant. The inequality constraint of "desirable output" and input variables means that "desirable output" and input variables are freely manageable. The equality constraint of "undesired output" indicates that "desirable output" and "undesired output" are weakly manageable together. In order to satisfy the null binding hypothesis theorem, the following two conditions (2) and (3) need to be emphasized for the DEA model:

$$
\sum_{\mathrm{k}=1}^{\mathrm{K}} \mathrm{b}_{\mathrm{ki}}^{\mathrm{t}}>0, \mathrm{i}=1, \ldots, \mathrm{I}
$$

Formula (2) indicates that each "undesired output" has at least one decision-making unit of production.

$$
\sum_{\mathrm{i}=1}^{\mathrm{I}} \mathrm{b}_{\mathrm{ki}}^{\mathrm{t}}>0, \mathrm{k}=1, \ldots, \mathrm{K}
$$

Formula (3) indicates that each decision unit produces at least one "undesired output".

\subsubsection{Non-Radial and Non-Angular Directional Distance Function (NDDF)}

This paper adopts the generalized non-radial and non-angular directional distance function (NDDF), which is defined as:

$$
\left.\overrightarrow{N D^{G}}\left(x, y, b ; g_{x}, g_{y}, g_{b},\right)=\sup \left\{\omega^{T} \beta:\left(x-\beta_{x} g_{x}, y+\beta_{y} g_{y}, b-\beta_{b} g_{b}\right)+\beta g \in P(x)\right)\right\}
$$

where, $\omega^{T}=\left(\omega^{x}, \omega^{y}, \omega^{b}\right)^{T}$ is the weight vector, representing the relative importance of each element. Assuming that the weights of input, desirable output and undesired output are all $1 / 3$, the input of the model is the fixed capital stock, the number of employees in the whole society at the end of the year, and the total energy consumption at the end of the year. The desirable output is real GDP, and the non-desirable output is $\mathrm{SO}_{2}$ and $\mathrm{COD}$, then the weight vector is $\omega^{T}=(1 / 9,1 / 9,1 / 9,1 / 3,1 / 6,1 / 6) T$ and the relaxation variable is $\beta=(\beta x, \beta y, \beta b) T \geq 0$, which represents the proportion of factors changing; $g=(g x, g y, g b)$ as the output expansion in the direction of the vector, changing the direction of said elements. Select $g=(-x, y,-b)$, as the input $(x)$ decreases, the "desirable output" $(y)$ increases proportionately, and the "undesirable output" $(b)$ decreases proportionately. This means that $\beta$ is compressed, while the "desirable output" $(y)$ is increasing, and the largest possible number of "undesired output" $(b)$ is under control. The non-radial directional distance function can include three conditions, namely, input reduction, GDP increase and energy saving and emission reduction, into the analysis framework.

\subsubsection{Global Non-Radial Directional Diststance Function (GNDDF)}

This paper quotes the method proposed by Zhou et al. [43] and Pastor et al. [44]. The global non-radial directional distance function (GNDDF) index was established by 
combining the concept of global Malmquist productivity with the directional distance

function. The GNDDF index was solved by constructing the following linear programming:

$$
\begin{gathered}
\overrightarrow{N D}^{G}\left(x^{t}, y^{t}, b^{t} ; g_{x}, g_{y}, g_{b},\right)=\operatorname{Max} \omega_{k} \beta_{K}^{G t}+\omega_{L} \beta_{L}^{G t}+\omega_{E} \beta_{E}^{G t}+\omega_{Y} \beta_{Y}^{G t}+\omega_{C} \beta_{C}^{G t}+\omega_{S} \beta_{S}^{G t} \\
\text { S.T. } \sum_{h j=1}^{J} \sum_{h t=1}^{T} z_{j}^{t} Y_{j}^{t} \geq\left(1+\beta_{Y}^{G t}\right) Y_{j}^{t}, \sum_{h j=1}^{J} \sum_{h t=1}^{T} z_{j}^{t} K_{j}^{t} \leq\left(1-\beta_{k}^{G t}\right) K_{j^{\prime}}^{t} \\
\sum_{h j=1}^{J} \sum_{h t=1}^{T} z_{j}^{t} L_{j}^{t} \leq\left(1-\beta_{L}^{G t}\right) L_{j^{\prime}}^{t}, \sum_{h j=1}^{J} \sum_{h t=1}^{T} z_{j}^{t} E_{j}^{t} \leq\left(1-\beta_{E}^{G t}\right) E_{j^{\prime}}^{t} \\
\sum_{h j=1}^{J} \sum_{h t=1}^{T} z_{j}^{t} Y_{j}^{t}=\left(1=\beta_{c}^{G t}\right) C_{j^{\prime}}^{t} \sum_{h j=1}^{J} \sum_{h t=1}^{T} z_{j}^{t} S_{j}^{t} \leq\left(1-\beta_{S}^{G t}\right) S_{j^{\prime}}^{t} \\
z_{j} \geq 0 ; j=1,2, \ldots, J ; \beta_{K}^{G t} \geq 0, \beta_{L}^{G t} \geq 0, \beta_{E}^{G t} \geq 0, \beta_{Y}^{G t} \geq 0, \beta_{C}^{G t} \geq 0, \beta_{S}^{G t} \geq 0
\end{gathered}
$$

Similarly, $t$ and $t+1$ global non-radial directional distance functions can be constructed, respectively, and four kinds of distance function values can be obtained. The GNDDF index can be further decomposed into the global technical efficiency index (GNDDFEC) and the global technical progress index (GNDDFTC).

$$
\begin{aligned}
& \mathrm{GNDDF}^{t, t+1}=\frac{\overrightarrow{D_{0}^{G}}\left(X^{t}, Y^{t}, b^{t} ; g_{x^{t}}, g_{y^{t}}, g_{b^{t}}\right)}{1+\overrightarrow{D_{0}^{G}}\left(X^{t+1}, Y^{t+1}, b^{t+1} ; g_{x^{t+1}}, g_{y^{t+1}}, g_{b^{t+1}}\right)} \\
& =\frac{1+\overrightarrow{D_{0}^{t}}\left(X^{t}, Y^{t}, b^{t} ; g_{x^{t}}, g_{y^{t}}, g_{b^{t}}\right)}{1+\overrightarrow{D_{0}^{t+1}}\left(X^{t+1}, Y^{t+1}, b^{t+1} ; g_{x^{t+1}}, g_{y^{t+1}}, g_{b^{t+1}}\right)} \\
& \times \frac{\frac{1+\overrightarrow{D_{0}^{G}}\left(X^{t}, Y^{t}, b^{t} ; g_{x^{t}}, g_{y^{t}}, g_{b^{t}}\right)}{1+\overrightarrow{D_{0}^{t}}\left(X^{t}, Y^{t}, b^{t} ; g_{x^{t}}, g_{y^{t}}, g_{b^{t}}\right)}}{\frac{\overrightarrow{D_{0}^{G}}\left(X^{t+1}, Y^{t+1}, b^{t+1} ; g_{x^{t+1}}, g_{y^{t+1}}, g_{b^{t+1}}\right)}{1+D_{0}^{t+1}\left(X^{t+1}, Y^{t+1}, b^{t+1} ; g_{x^{t+1}}, g_{y^{t+1}}, g_{b^{t+1}}\right)}}=\text { GNDDFEC }^{t, t+1} \times \text { GNDDFTC }^{, t, t+1}
\end{aligned}
$$

The GNDDFEC measures the movement of the environmental production frontier from $t+1$ period, while the GNDDFTC measures the change in the approximate degree between the actual production of each decision unit and the maximum possible output of the environmental production frontier from the $t$ to $t+1$ period. The GNDDFEC and GNDDFTC are greater than 0, respectively, indicating improvement of technical productivity and technical efficiency, while less than 0 indicates the opposite, and equal to 0 means unchanged.

\subsection{Variable Description}

\subsubsection{Explained Variable}

Green TFP (GTFP): This paper selects Malmquist productivity—the Luenberger index to handle the "undesirable output", the natural resources as inputs, and the elements of the pollutants as "undesired output" in the model.

\subsubsection{Explanatory Variable}

Capital investment: In the existing literature, the index of "fixed capital stock" is almost used as the substitution index of capital investment in the production function. In this study, the fixed capital stock (CNY 100 million) is also used as the proxy variable of investment expenditure. Using Zhang Jun (2004)'s algorithm, the capital stock in the base period is the initial capital stock of the province, which is divided by $10 \%$ of the total fixed capital formation in 1978 , and the depreciation rate is $9.6 \%$.

Labor input: Theoretically, labor input's calculation should be the sum of the number of all laborers in society multiplied by the average working time. Due to the availability of data, almost all empirical studies in China use the number of workers to represent labor input. In this study, the number of social employees by each year-end (ten thousand) is also used as the proxy variable of labor input. 
Resource input: Since the large-scale use of energy is the main cause of pollution and current energy consumption is mainly composed of coal, oil, and natural gas, the total energy consumption by year-end (tons of standard coal) was chosen as the index of resource input in this study.

Desirable output: According to the general practice in the existing research literature, the actual GDP of each province (100 million yuan) was selected as the desirable output, and the nominal GDP of the lagging seven provinces (cities) in recent years was converted into the real GDP for the year 1978 as the desirable output by using the GDP deflator.

Undesired outputs: The study was based on industrial waste gas sulfur dioxide emissions $\left(\mathrm{SO}_{2}\right)$ and industrial waste-water chemical oxygen demand emissions (COD) for the measurement of undesired output.

\subsection{Results}

The global non-radial directional distance function of the seven underdeveloped provinces (areas) was measured by MaxDEA, and the green TFP was calculated. The results are displayed in Table 1.

Table 1. Green total factor productivity (green TFP) from 2001 to 2019.

\begin{tabular}{cccc}
\hline Year & $\begin{array}{c}\text { The Green Total Factor } \\
\text { Productivity Index GNDDF }\end{array}$ & $\begin{array}{c}\text { Technical Efficiency } \\
\text { Index GNDDFEC }\end{array}$ & $\begin{array}{c}\text { Technical Progress } \\
\text { Index GNDDFTC }\end{array}$ \\
\hline 2001 & 1.00 & 0.99 & 1.01 \\
2002 & 0.99 & 1.03 & 0.96 \\
2003 & 0.99 & 1.00 & 0.99 \\
2004 & 0.99 & 1.00 & 0.99 \\
2005 & 1.00 & 1.06 & 0.94 \\
2006 & 1.00 & 1.02 & 0.99 \\
2007 & 1.00 & 1.01 & 0.99 \\
2008 & 1.01 & 1.01 & 1.00 \\
2009 & 1.01 & 1.00 & 1.01 \\
2010 & 1.01 & 0.98 & 1.03 \\
2011 & 1.00 & 0.98 & 1.02 \\
2012 & 1.01 & 1.01 & 1.00 \\
2013 & 1.03 & 1.02 & 1.01 \\
2014 & 1.02 & 1.01 & 1.01 \\
2015 & 1.04 & 1.02 & 1.02 \\
2016 & 1.04 & 1.01 & 1.02 \\
2017 & 1.04 & 0.91 & 1.14 \\
2018 & 1.03 & 0.99 & 1.10 \\
2019 & 1.04 & 0.97 & 1.09 \\
\hline Average & 1.01 & 1.00 & 1.01 \\
\hline
\end{tabular}

According to the results in Table 1, from 2001 to 2019 the average green total factor productivity of the lagging seven provinces (autonomous regions) is 1.01, with small fluctuations on the whole.

\section{Model Setting and Empirical Analysis}

\subsection{Model Setting}

There is no linear relationship between high-level industrial structure and green economic growth, and it is influenced by the rationalization of industrial structure, that is, there is a turning point in the relationship curve of green growth. This kind of turning point is called the threshold. Therefore, the industrial structure rationalization of the impact of green economic growth degree and direction are important factors. This paper adopts the panel threshold regression model to verify the non-linear relationship between the industrial structure upgrade and the green economic growth, and it identifies the 
threshold value. It provides a theoretical foundation for the government to adjust the industrial structure.

In this paper, the Hansen threshold regression model was used to replace the variables in the model with the variables after eliminating the individual effect, and the sum of squares of the estimated coefficient and the regression equation were obtained through OLS regression (Hansen 1993). The critical value was obtained by the bootstrap method, while the corresponding P value was obtained via the LR test. If the P value is smaller than the critical value, the threshold effect exists; otherwise, it does not exist. According to the test method put forward by Hansen, in the regression model, rationalization of the industrial structure is taken as the threshold variable. The number and value of the threshold are estimated, and the following nonlinear panel regression model is established in the form of Formula (7):

$$
y_{i t}=\beta_{0}+\beta_{1} \mathrm{x}_{i t} \mathrm{I}\left(\mathrm{q}_{i t}<a_{1}\right)+\beta_{2} \mathrm{x}_{i t} \mathrm{I}\left(a_{1} \leq \mathrm{q}_{i t}<a_{2}\right)+\mathrm{K}+\beta_{n} \mathrm{x}_{i t} \mathrm{I}\left(\mathrm{q}_{i t} \geq a_{n}\right)+\delta \mathrm{Z}_{i t}+\varepsilon_{i t}+\mu_{i}
$$

where in the explanatory variable $\mathrm{q}_{i t}$ is the threshold variable and $a_{1}, a_{2}, \mathrm{k}$, and $a_{n}$ are the threshold values to be estimated. We set $n$ threshold values and then $n+1$ intervals were obtained. Within each interval, the explanatory variable is $y_{i t}$. There is heterogeneity in the influence. The corresponding coefficients are $\beta_{1}, \beta_{2}, \mathrm{~K}$, and $\beta_{n+1} . \mathrm{I}(\cdot)$ is an indicator function. If the conditions in parentheses are not met, the value is 0 ; otherwise, the value is 1. $x_{i t}$ is the explanatory variable. $Z_{i t}$ is the control variable. $\beta_{0}$ is the intercept term. $u_{i}$ is the individual effect, and $\varepsilon_{i t}$ represents the random perturbation term. Under the influence of industrial structure rationalization, in order to obtain the threshold value of the advanced effect of the industrial structure upgrade level on the green economic growth, the final panel threshold model was set in the form of Formula (8).

$$
\mathrm{GTFP}_{i t}=\beta_{0}+\beta_{1 i t} \mathrm{TS}_{i t}\left(\mathrm{TL}_{i t}<a_{1}\right)+\beta_{2} \mathrm{TS}_{i t}\left(a_{1} \leq \mathrm{TL}_{i t}<a_{2}\right)+\beta_{n} \mathrm{TS}_{i t}\left(\mathrm{TL}_{i t} \geq a_{n}\right)+\delta Z_{i t}+\varepsilon_{i t}+\mu_{i}
$$

In Formula (8), $i$ represents the province $(i=1,2, \ldots, 7), t$ represents year $(t=2000$, $2001, \ldots, 2018) . \mu_{i}$ represents an unobservable individual feature, and $\varepsilon_{i t}$ is the random disturbance term. $Z_{i t}$ is a series of control variables; $\varepsilon_{i t}$ is the random disturbance term.

\subsection{Variable Description}

\subsubsection{Variable Setting}

(1) Explained Variable

Green TFP(GTFP)

(2) Explanatory Variable

Industrial structure upgrading index (TS): in this index, the ratio of the tertiary industry output value to the secondary industry output value is used to measure the industrial structure upgrading index.

(3) Threat Variable

The industrial structure rationalization index (TL) is measured by employing the industrial structure synergy coefficient as follows:

$$
\mathrm{TL}=\frac{\sum_{\mathrm{i}=1}^{\mathrm{n}}\left(\frac{Y_{\mathrm{i}}}{\mathrm{Y}}\right)\left(\frac{\mathrm{L}_{\mathrm{i}}}{\mathrm{L}}\right)}{\sqrt{\sum_{\mathrm{i}=1}^{\mathrm{n}}\left(\frac{Y_{\mathrm{i}}}{\mathrm{Y}}\right)^{2}} \sqrt{\sum_{\mathrm{i}=1}^{\mathrm{n}}\left(\frac{\mathrm{L}_{\mathrm{i}}}{\mathrm{L}}\right)^{2}}}
$$

where i represents industry, $Y$ represents gross production, $Y_{i} / Y$ represents the proportion of the output value of department I in total, and $\mathrm{L}_{\mathrm{i}} / \mathrm{L}$ represents the proportion of the number of employed people in sector I to the total number. The value range of TL is $0-1$. The closer TL is to 1 , the better the synergy between the change of employment structure and the change of industrial structure in an economy, and the higher the degree of industrial structure rationalization.

(4) Control Variables 
Referring to existing literature, this article selects five control variables. Education level (EDU) refers to the higher education level of the resident. It is generally believed that a higher average level of education is more conducive to promoting technological progress and innovation, thereby facilitating economic development. The ratio of the sum of students in common colleges and universities to the total population is selected to measure the level of education. The financial development level (FI) refers to the ratio of total social financial activities to total economic activities in a given period. Financial development mainly affects the conversion efficiency of savings and investment and affects the scale and speed of monetary capital accumulation, thus changing the flow direction of industrial capital, the allocation structure, and the allocation of production factors. As a result, it has an influence on the industrial structure. The ratio of the sum of bank deposits and loans to GDP is selected to measure the level of regional financial development. The fixed asset investment rate (IN) is measured through the proportion of fixed asset investment in GDP. The urbanization rate (CZ) and Internet penetration rate (IP) directly use the statistical index values of the National Bureau of Statistics.

\subsubsection{Empirical Results}

This paper used Stata 16 software to estimate the model successively with a single, double, and triple threshold. For the F test of the single threshold, the null hypothesis means that there is no threshold, and the null hypothesis of the double threshold is that there is one threshold, and so on. The result shows in Table 2.

Table 2. Panel threshold effect test (the BS degree is 200).

\begin{tabular}{cccccc}
\hline Threshold & Fstat & Prob & Crit10 & Crit5 & Crit1 \\
\hline Single & 1.93 & 0.830 & 10.787 & 13.196 & 19.829 \\
Double & 12.64 & 0.090 & 12.150 & 14.420 & 18.410 \\
Triple & 2.27 & 0.655 & 7.884 & 16.904 & 39.420 \\
\hline
\end{tabular}

As shown in Table 2, in the single threshold effect test, the F statistic is 1.93, and the $p$ value is 0.83 . In the triple threshold test, the F value is 2.27 , the $p$ value is 0.655 , and the null hypothesis cannot be rejected at a significance level of 0.1 , showing that there are not one or three threshold values. In the double threshold test, the F value is 12.64 , while the $p$ value is 0.09 . The null hypothesis is rejected at the significance level of 0.1 , showing the existence of the double threshold value. In this case, the regression equation is determined as follows:

$$
\begin{gathered}
\mathrm{GTFP}_{i t}=\beta_{0}+\beta_{1} \mathrm{TS}_{i t}\left(\mathrm{TL}_{i t}<a_{1}\right)+\beta_{2} \mathrm{TS}_{i t}\left(a_{1} \leq \mathrm{TL}_{i t}<a_{2}\right)+\beta_{3} \mathrm{TS}_{i t}\left(\mathrm{TL}_{i t} \geq a_{n}\right)+\beta_{4} \mathrm{FI}_{i t} \\
+\beta_{5} \mathrm{OP}_{i t}+\beta_{6} \mathrm{REDU}_{i t}+\beta_{7} \mathrm{IN}_{i t}+\beta_{8} \mathrm{CZ}_{i t}+\beta_{9} \mathrm{IP}_{i t}+\varepsilon_{i t}+\mu_{i}
\end{gathered}
$$

An LR test was conducted according to Equation (10) of the regression equation, and the threshold parameter results are shown in Figure 1. There were two threshold values in the sample, and the specific values are shown in Table 2.

Figure 1 and Table 3 show that upgrading industrial structures influences the green TFP, and the size of the industrial structure rationalization is separated into three phases: the first phase of the industrial structure rationalization is less than 0.661 , the second phase of the industrial structure rationalization is greater than 0.661 and less than 0.673 , and the third stage for the rationalization of industrial structure is greater than 0.673 .

Table 3. The threshold value.

\begin{tabular}{cccc}
\hline Model & Threshold & Lower & Upper \\
\hline Th-1 & 0.661 & 0.624 & 0.671 \\
Th-2 & 0.673 & 0.648 & 0.673 \\
\hline
\end{tabular}




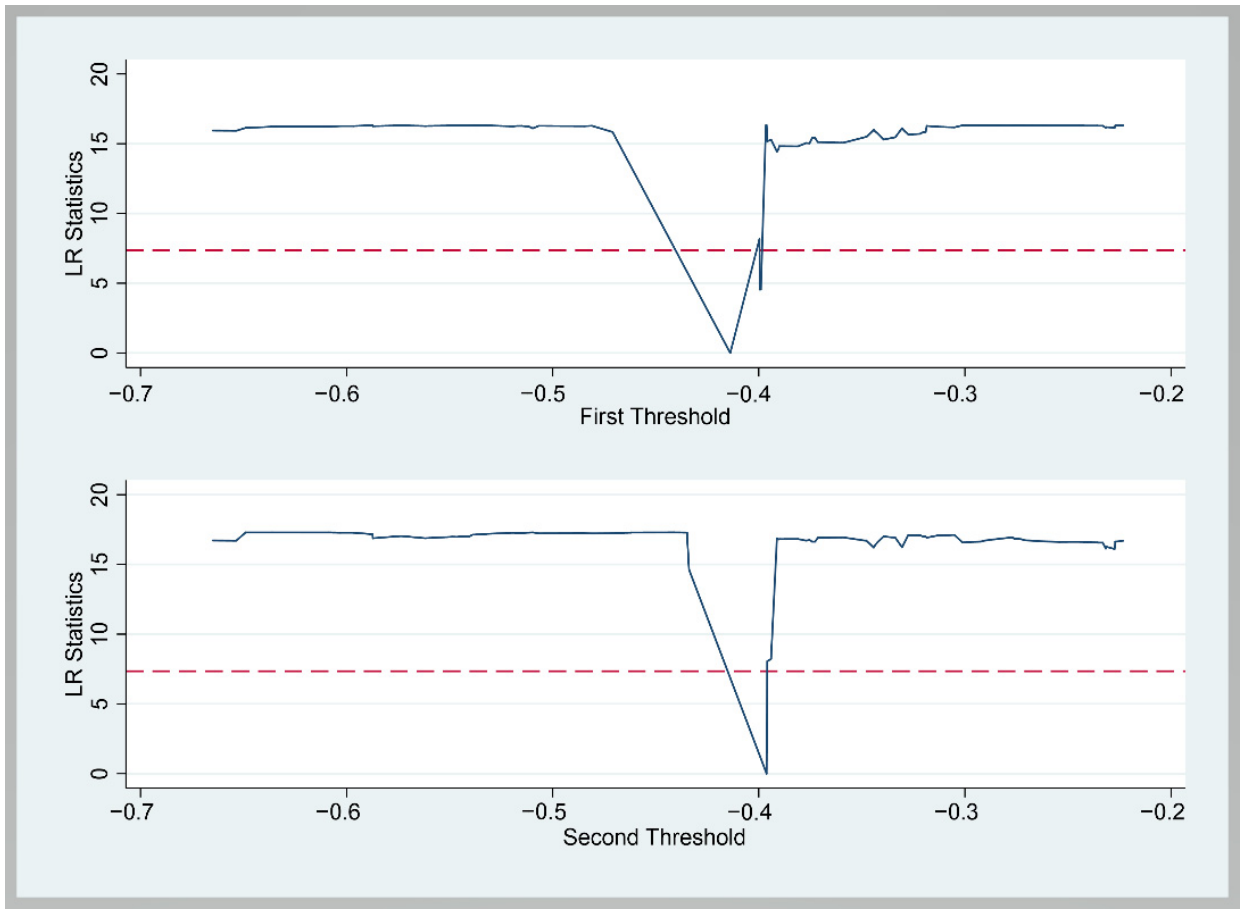

Figure 1. The threshold parameters of the regression equation.

The reasonability of piecewise consideration can be determined by combining the panel threshold regression model with the panel model's $R^{2}$ for comparison. $R^{2}$ of the threshold regression model is determined to be less than $R^{2}$ of the panel model, which indicates that the panel model is reasonable and cannot be used for piecewise research; otherwise, the threshold model is more reasonable. The results are displayed in Table 4 .

Table 4. Fixed-effect panel regression model.

\begin{tabular}{|c|c|c|c|c|c|c|}
\hline \multirow{2}{*}{$\begin{array}{c}\text { GTFP } \\
\text { TS }\end{array}$} & \multirow{2}{*}{$\begin{array}{c}\text { Coef. } \\
-0.463^{* *}\end{array}$} & \multirow{2}{*}{$\begin{array}{c}\text { Std. Err. } \\
0.216\end{array}$} & \multirow{2}{*}{$\begin{array}{c}\mathbf{t} \\
-2.14\end{array}$} & \multirow{2}{*}{$\begin{array}{c}p>|t| \\
0.034\end{array}$} & \multicolumn{2}{|c|}{ [95\% Conf. Interval] } \\
\hline & & & & & -0.891 & -0.035 \\
\hline FI & 0.023 & 0.036 & 0.62 & 0.535 & -0.049 & 0.094 \\
\hline EDU & $1.282^{* * *}$ & 0.322 & 3.98 & 0.000 & 0.644 & 1.920 \\
\hline IN & $-0.475^{* * *}$ & 0.083 & -5.7 & 0.000 & -0.640 & -0.310 \\
\hline $\mathrm{CZ}$ & $0.784^{* * *}$ & 0.254 & 3.08 & 0.003 & 0.281 & 1.287 \\
\hline $\mathrm{IP}$ & $-0.157^{* * *}$ & 0.041 & -3.78 & 0.000 & -0.239 & -0.075 \\
\hline _cons & $-6.171^{* * *}$ & 0.908 & -6.8 & 0.000 & -7.969 & -4.374 \\
\hline R-squared & 0.439 & & & & & \\
\hline Hausman & 0.000 & & & & & \\
\hline
\end{tabular}
are in parentheses.

The results of the $\mathrm{F}$ value test and the Hausman test show that the $p$ value is equal to 0 , indicating that the panel model should choose the fixed-effect panel model, and $\mathrm{R}^{2}$ of the two models is compared; it can be found that the fixed-effect model is lower than the threshold regression model, indicating that the threshold regression model is more reasonable. The threshold regression results are displayed in Table 5. 
Table 5. Panel threshold regression model (bs(200)).

\begin{tabular}{|c|c|c|c|c|c|c|}
\hline \multirow{2}{*}{$\begin{array}{c}\text { GTFP } \\
\text { TS1 }\end{array}$} & \multirow{2}{*}{$\begin{array}{c}\text { Coef. } \\
-1.485^{*}\end{array}$} & \multirow{2}{*}{$\begin{array}{c}\text { Std. Err. } \\
0.791\end{array}$} & \multirow{2}{*}{$\frac{\mathbf{t}}{-1.88}$} & \multirow{2}{*}{$\begin{array}{c}p>|\mathbf{t}| \\
0.063\end{array}$} & \multicolumn{2}{|c|}{ [95\% Conf. Interval] } \\
\hline & & & & & -3.051 & 0.080 \\
\hline TS2 & $11.625^{* * *}$ & 2.785 & 4.17 & 0.000 & 6.110 & 17.140 \\
\hline TS3 & $-0.394 *$ & 0.209 & -1.89 & 0.062 & -0.807 & 0.020 \\
\hline FI & 0.009 & 0.034 & 0.27 & 0.785 & -0.058 & 0.076 \\
\hline EDU & $1.186^{* * *}$ & 0.301 & 3.95 & 0.000 & 0.591 & 1.781 \\
\hline IN & $-0.477^{* * *}$ & 0.077 & -6.17 & 0.000 & -0.631 & -0.324 \\
\hline $\mathrm{CZ}$ & $0.584^{* *}$ & 0.242 & 2.42 & 0.017 & 0.105 & 1.062 \\
\hline IP & $-0.120 * * *$ & 0.040 & -3 & 0.003 & -0.199 & -0.041 \\
\hline _cons & $-5.171^{* * *}$ & 0.884 & -5.85 & 0.000 & -6.921 & -3.421 \\
\hline R-squared & 0.524 & & & & & \\
\hline
\end{tabular}

On the basis of the panel threshold regression results obtained in Table 5, it is shown that there are double thresholds within the sample interval. When the rationalization index of the industrial structure is less than 0.661 , there is a significant negative relationship between industrial structure upgrading and green TFP at the significance level of 0.10 , and the regression coefficient is -1.485 . When the industrial structure rationalization index is greater than 0.661 and less than 0.673 , there is a significant positive relationship between industrial structure upgrading. When green TFP is at the 0.01 significance level, the regression coefficient is 11.625. When the rationalization index of the industrial structure is greater than 0.673 , there is a significant negative relationship between industrial structure upgrading. When green TFP is at the $10 \%$ significance level, the regression coefficient is -0.394 . The effect of the industrial structure upgrading on green TFP is initially negative, and then positive and negative, which means that when the rationalization degree of the industrial structure is at a relatively low level, the improvement of advanced levels of industrial structure affects the improvement of green total factor productivity. At this stage, the industrial structure foundation is poor, the structure of various industries is not coordinated, and the overall development is not balanced in underdeveloped areas. Meanwhile, there is no reasonable basis for industrial structure development, and the adjustment thinking of industrial policy in underdeveloped areas should not focus on the improvement of advanced levels of industrial structure; otherwise, the green TFP will be affected. When the industrial structure rationalization index is greater than 0.661 and less than 0.673 , high-level industrial structures and green TFP display a significantly positive relationship, which shows that with a high degree of industrial structure rationalization, high-level industrial structure development promotes green TFP significantly in underdeveloped areas. In the stage of relatively reasonable allocations of resources among industries, the industry-coordinated development degree is higher, and the industry's output achieves an improved balance among workers. The growth of the secondary industry lays a good industrial foundation and driving force for the further development of the tertiary industry. Based on this, the economic growth can move in the service-oriented direction, and the development of green TFP can be accelerated by vigorously improving industrial structure. When the industrial structure rationalization index is greater than 0.661 , a clearly negative relationship below the 0.10 significance level exists between the high-level industrial structure and green TFP. This stage indicates that the industrial structure rationalization degree is higher than equilibrium (0.673), further improving the level of industrial structure upgrading, rationalization, the green economic development in underdeveloped areas, and the level-shift-inhibiting effect.

The rationalization indexes of industrial structure in underdeveloped areas are mostly in the first interval. When the industrial base is weak and the level of rationalization is low, if the underdeveloped areas excessively pursue industrial structure upgrading, the unbalanced investment of factor resources may affect the good interaction between the three industries, thus affecting the quality of industrial economic development. 
The control variable financial development degree (FI) has no obvious influence on the green TFP advancement. Finance is the core of modern economy. It has an influence on green TFP through five aspects: capital formation, capital allocation, credit creation, information disclosure, and risk prevention and diversification, and it plays an important role in optimizing resource allocation and promoting optimization of green TFP. This may be due to the relatively low level of financial development in underdeveloped areas, which failed to play a role in advancing green economic growth.

The control variable education level (EDU) has a significantly positive effect on green TFP. From the perspective of consumption, improvements in education levels will change the structure of product consumption demand to some extent and then stimulate green TFP increase.

The coefficient of the fixed-asset investment rate (IN) of the control variable is significantly negative, showing that the fixed asset investment is not enough to promote green TFP. Fixed-asset investment is an important means of resource allocation, and the scale and structure of investment play a decisive role in regional green TFP. The economic development of underdeveloped areas mainly depends on investment, which determines the industrial composition of economic growth, and the proportion of investment in the three industries decides the output proportion of the three industries. The fixed asset investment in underdeveloped areas has a negative influence on green TFP, which indicates that the investment structure is unreasonable, emphasizing the mode of heavy industry development and affecting the improvement of green TFP.

The influence of the control variable urbanization rate $(\mathrm{CZ})$ on green TFP is significantly positive. Urbanization in underdeveloped areas is still at a relatively low level, and the process of urbanization can effectively promote economic growth.

The influence of the control variable network penetration rate (IP) on green TFP is significantly negative. Network economy is a new type of economic form, and its development is affected by many factors, including capital, market, and technology. A region's economic development affects the development of Internet penetration, and as the quality of the network economy in underdeveloped areas is still at low levels, internet penetration ascension failed to advance the coordinated development of industry and service industry and has an inhibitory effect on green TFP.

\subsubsection{Robustness Test of the Panel Threshold Effect}

On the basis of the unchanged settings of the original model, we replaced similar control variables to observe whether the model is still valid. First of all, by replacing education level with the per capita level of education, result shows that, under the 0.05 significance level, there are two thresholds. The threshold has not changed, the core variable coefficient of plus or minus is unchanged, and the coefficient of size change is not obvious. Thus, it appears that the regression estimate results are reliable, and the robustness test results are displayed in Table 6.

Table 6. Robustness test results.

\begin{tabular}{ccccc}
\hline GTFP & \multicolumn{2}{c}{ The Original Results } & \multicolumn{2}{c}{ Replace Educational Levels } \\
\hline & Coef. & $\mathbf{t}$ & Coef. & $\mathbf{t}$ \\
\hline TS1 & $-1.485^{*}$ & -1.88 & $-1.828^{* *}$ & -2.19 \\
TS2 & $11.625^{* * *}$ & 4.17 & $11.991^{* * *}$ & 4.05 \\
TS3 & $-0.394^{*}$ & -1.89 & $-0.502^{* *}$ & -2.27 \\
FI & $0.009^{* *}$ & 0.27 & 0.017 & 0.47 \\
EDU & $1.186^{* *}$ & 3.95 & -0.040 & -0.42 \\
IN & $-0.477^{* * *}$ & -6.17 & $-0.467^{* * *}$ & -5.21 \\
\hline
\end{tabular}


Table 6. Cont.

\begin{tabular}{ccccc}
\hline GTFP & \multicolumn{2}{c}{ The Original Results } & \multicolumn{2}{c}{ Replace Educational Levels } \\
\hline \multicolumn{1}{c}{ Coef. } & $\mathbf{t}$ & Coef. & $\mathbf{t}$ \\
\hline CZ & $0.584^{* *}$ & 2.42 & $1.051^{* * *}$ & 4.39 \\
IP & $-0.120^{* * *}$ & -3 & $-0.084^{*}$ & -1.7 \\
Constant & $-5.171^{* * *}$ & -5.85 & $-4.541^{* * *}$ & -4.14 \\
\hline R-squared & 0.524 & 0.439 \\
Note: ${ }^{* * *}, * *$ and ${ }^{*}$ indicate significant at the significance level of $0.01,0.05$, and 0.10, respectively; The values of $\mathrm{t}$ \\
are in parentheses.
\end{tabular}

\section{Discussion and Policy Recommendations}

Under the constraints of resources and environment, identifying the best way to improve green TFP, releasing the dividend of industrial structure transformation, and stimulating new driving forces of economic development are important issues for underdeveloped areas to achieve rapid economic development and poverty alleviation. This study finds out that the influence of the advancement of industrial structure on green economic growth exists in a nonlinear relationship and there is a "threshold" for industrial structure rationalization. This section summarizes the main findings of this paper.

\subsection{Study Results and Discussion}

6.1.1. There Are Two "Rationalization Points" with Efficiency Demarcation between Industrial Structure Evolution and Green Growth

This paper has analyzed data from a period spanning 10 years in seven provinces of China. The results show that industrial structure upgrading and green total factor productivity (green TFP) do not have a fundamentally linear relationship, but are affected by the industrial structure rationalization point. There are points to highlight: (1) within the threshold value interval $[0.661,0.673]$ of the rationalization of industrial structure, the highlevel industrial structure development has a promoting effect on the improvement of green TFP. (2) Outside the threshold range, the improvement of high-level industrial structures has an inhibitory effect on green TFP. (3) From 2000 to 2019, the industrial development stage of seven underdeveloped provinces (areas) in China lagged behind developed areas, among which the industrial structure rationalization index was in the range of from less than 0.661 to less than 0.673 ; after 2014, the industrial structure rationalization index of most underdeveloped provinces was more than 0.673 . Since the industrial structure rationalization is mostly outside the threshold range of 0.673 , the upgrading of industrial structure has an inhibiting effect on the improvement of green TFP. Therefore, we should pay attention to the rationalization of the secondary and tertiary industry input, and not deliberately emphasize the growth of the tertiary industry. Otherwise, the efficiency of economic development may be reduced, which is not conducive to the improvement of economic level.

6.1.2. Changes in Industrial Structure Will Affect the Results of Green Total Factor Productivity Growth

Green TFP is additional productivity that counts resources as inputs and environmental pollution emissions as "undesirable" outputs. Total factor productivity mainly comes from two aspects. The first is the efficiency of resource reallocation, including the industrial transfer caused by the difference of factor productivity between regions. For example, after China's economy passed the "Lewis turning point" in 2004, labor-intensive industries began to move from the east to the central and western regions. In addition, the factor productivity differences among different industrial sectors in the region also cause the flow and reconfiguration of resource factors. For example, enterprises with higher productivity gain the ability to expand reproduction, forming scale efficiency. Second, the production efficiency of micro-entities in industrial sectors is mainly obtained through large-scale production and technological innovation. According to the research results of 
some scholars on American enterprises, the resource reconfiguration within the industrial sector, such as the entry, exit, expansion, and contraction of manufacturers within the manufacturing industry, contributes as much as $30-50 \%$ to the productivity increase.

6.1.3. Driving Forces of Green Total Factor Productivity Growth Mainly Include Technological Progress Efficiency and Scale Efficiency

The driving forces of green TFP growth mainly include technological progress efficiency and scale efficiency, which are the results of technological progress and the optimal allocation of resources. With rapid economic growth, the underdeveloped areas mainly obtain the efficiency of resource reallocation through the transfer of labor force between departments and regions, thus obtaining the improvement of TFP. At this point, in the process of accelerating industrial development by undertaking labor-intensive manufacturing transferred from one region to another, less-developed regions should attach more importance to ecological benefits.

\subsection{Enlightenment of Industrial Structure Adjustment Path}

\subsubsection{Avoid the Path of Premature and Excessive Industrial Technological Upgrading}

Underdeveloped areas should choose and be introduced to more suitable industries, which try to collocate and integrate the existing industry. In the stage of economic revitalization, it is important to continuously improve the efficiency of resource allocation, adjust the rationalization level of industrial structure, coordinate the factor input ratio among various industries, and avoid introducing and developing unsuitable industries and technologies too early, so as to avoid low investment efficiency and ecological sacrifice.

\subsubsection{Actively Adjust the Green Total Factor Productivity}

In addition to capital, labor, land, and other traditional elements of cross-industry regulation and allocation, it is also necessary to adopt a combination of government regulation and market orientation of environmental control means, including the development of new energy sources, the use of energy-saving raw materials, increasing the added value, increasing unit productivity, and increasing capital turnover and other technology and management methods. Staff should be trained and educated on energy conservation, emission reduction, and green development.

Author Contributions: Conceptualization, G.L., D.Y. and L.K.; methodology, D.Y.; software, D.Y.; validation, G.L., D.Y. and L.K.; resources, D.Y.; data curation, D.Y. and L.K.; writing-original draft preparation, D.Y.; writing-review and editing, G.L., D.Y. and L.K.; visualization, D.Y.; supervision L.K. All authors have read and agreed to the published version of the manuscript.

Funding: 2018 National Social Science Foundation of China (Project Name: Research on Improving Poverty Allowance Industrial Efficiency by Service Industry in Yunnan, Guangxi and Guizhou Rocky Desertification Area, No.: 18XMZ073). 2017 Guangxi Social Science Fund (Project Name: Research on the Core Economic Carriage of Rural Revitalization in Old, Minority, Border and Poor Areas, No.: 17AZT14). We gratefully acknowledge the above financial support.

Data Availability Statement: Data available in a publicly accessible repository that does not issue DOIs Publicly available datasets were analyzed in this study. This data can be found here: http:/ / www.stats. gov.cn/tjsj/ndsj/ accessed on 1 June 2021.

Acknowledgments: The authors would like to thank Yue Li for his valuable suggestions. Lastly, the authors thank anonymous reviewers for fruitful suggestions.

Conflicts of Interest: The authors declare no conflict of interest.

\section{References}

1. Wang, Q.; Jiang, R. Is China's Economic Growth Decoupled from Carbon Emissions? J. Clean. Prod. 2019, $225,1194-1208$. [CrossRef]

2. Lee, S.; Oh, D.-W. Economic Growth and the Environment in China: Empirical Evidence Using Prefecture Level Data. China Econ. Rev. 2015, 36, 73-85. [CrossRef] 
3. Chen, L.; Xu, L.; Xu, Q.; Yang, Z. Optimization of Urban Industrial Structure under the Low-Carbon Goal and the Water Constraints: A Case in Dalian, China. J. Clean. Prod. 2016, 114, 323-333. [CrossRef]

4. Kemp, R.; Never, B. Green Transition, Industrial Policy, and Economic Development. Oxf. Rev. Econ. Policy 2017, 33, 66-84. [CrossRef]

5. Bernardi, F.; Garrido, L. Is There a New Service Proletariat? Post-Industrial Employment Growth and Social Inequality in Spain. Eur. Sociol. Rev. 2008, 24, 299-313. [CrossRef]

6. Kuai, P.; Li, W.; Cheng, R.; Cheng, G. An Application of System Dynamics for Evaluating Planning Alternatives to Guide a Green Industrial Transformation in a Resource-Based City. J. Clean. Prod. 2015, 104, 403-412. [CrossRef]

7. Petrenko, E.; Pritvorova, T.; Dzhazykbaeva, B. Sustainable Developmet Processes: Service Sector in Post-Industrial Economy. J. Secur. Sustain. Issues 2018, 7, 781-791. [CrossRef]

8. Wei, W.; Zhang, M. The Non-Linear Impact of Industrial Structure on $\mathrm{CO}_{2}$ Emissions in China. Appl. Econ. Lett. 2020, 27, 576-579. [CrossRef]

9. Pitkänen, K.; Antikainen, R.; Droste, N.; Loiseau, E.; Saikku, L.; Aissani, L.; Hansjürgens, B.; Kuikman, P.J.; Leskinen, P.; Thomsen, M. What Can Be Learned from Practical Cases of Green Economy?-Studies from Five European Countries. J. Clean. Prod. 2016, 139, 666-676. [CrossRef]

10. Deutz, P.; Gibbs, D. Eco-Industrial Development and Economic Development: Industrial Ecology or Place Promotion? Bus. Strategy Environ. 2004, 13, 347-362. [CrossRef]

11. Guerrieri, P.; Meliciani, V. Technology and International Competitiveness: The Interdependence between Manufacturing and Producer Services. Struct. Chang. Econ. Dyn. 2005, 16, 489-502. [CrossRef]

12. Drucker, J. Regional Industrial Structure Concentration in the United States: Trends and Implications. Econ. Geogr. 2011, 87, 421-452. [CrossRef]

13. Zhao, J.; Tang, J. Industrial Structure Change and Economic Growth: A China-Russia Comparison. China Econ. Rev. 2018, 47, 219-233. [CrossRef]

14. Mah, J.S. Industrial Policy and Economic Development: Korea's Experience. J. Econ. Issues 2007, 41, 77-92. [CrossRef]

15. Timmer, M.P.; Szirmai, A. Productivity Growth in Asian Manufacturing: The Structural Bonus Hypothesis Examined. Struct. Chang. Econ. Dyn. 2000, 11, 371-392. [CrossRef]

16. Fomina, A.V.; Berduygina, O.N.; Shatsky, A.A. Industrial Cooperation and Its Influence on Sustainable Economic Growth. Entrep. Sustain. Issues 2018, 5, 467-479. [CrossRef]

17. Dauth, W.; Suedekum, J. Globalization and Local Profiles of Economic Growth and Industrial Change. J. Econ. Geogr. 2016, 16, 1007-1034. [CrossRef]

18. Gürlük, S. Economic Growth, Industrial Pollution and Human Development in the Mediterranean Region. Ecol. Econ. 2009, 68, 2327-2335. [CrossRef]

19. Chang, D.-S.; Yeh, L.-T.; Chen, Y. The Effects of Economic Development, International Trade, Industrial Structure and Energy Demands on Sustainable Development. Sustain. Dev. 2014, 22, 377-390. [CrossRef]

20. Mokyr, J.; Nye, J.V.C. Distributional Coalitions, the Industrial Revolution, and the Origins of Economic Growth in Britain. South. Econ. J. 2007, 74, 50-70. [CrossRef]

21. Zhixin, Z.; Qiao, X. Low-Carbon Economy, Industrial Structure and Changes in China's Development Mode Based on the Data of 1996-2009 in Empirical Analysis. Energy Procedia 2011, 5, 2025-2029. [CrossRef]

22. Binh, K.B.; Park, S.Y.; Shin, B.S. Financial Structure Does Matter for Industrial Growth: Direct Evidence from OECD Countries; Social Science Research Network: Rochester, NY, USA, 2006. [CrossRef]

23. Borgersen, T.-A.; King, R.M. Export-Led Growth in Transition Economies. East. Eur. Econ. 2014, 52, 33-54. [CrossRef]

24. Fang, C. How China's Economic Growth Steers to Total Factor Productivity-driven. China Pollinat. 2013, 1, 56-71.

25. Lin, Y. New structural economics: The framework of reconstructing development economics. Econ. Q. 2011, 10, 1-32. [CrossRef]

26. Jin, F.; Jin, R. The spatial effect of agricultural industrial structure change on green total factor productivity growth. J. Huazhong Agric. Univ. (Soc. Sci. Ed.) 2020, 1, 124-134. [CrossRef]

27. Ambroise, L.; Prim-Allaz, I.; Teyssier, C.; Peillon, S. The Environment-Strategy-Structure Fit and Performance of Industrial Servitized SMEs. J. Serv. Manag. 2017, 29, 301-328. [CrossRef]

28. Fagerberg, J. Technological Progress, Structural Change and Productivity Growth: A Comparative Study. Struct. Chang. Econ. Dyn. 2000, 11, 393-411. [CrossRef]

29. Singh, L. Technological Progress, Structural Change and Productivity Growth in the Manufacturing Sector of South Korea. World Rev. Sci. Technol. Sustain. Dev. 2004, 1, 37-49. [CrossRef]

30. Gan, C.; Zheng, R.; Yu, D. Impact of industrial structure change on economic growth and fluctuation in China. Econ. Res. J. 2011, 5, 4-16.

31. Soytas, U.; Sari, R. Energy Consumption, Economic Growth, and Carbon Emissions: Challenges Faced by an EU Candidate Member. Ecol. Econ. 2009, 68, 1667-1675. [CrossRef]

32. Yuan, X.; Mu, R.; Zuo, J.; Wang, Q. Economic Development, Energy Consumption, and Air Pollution: A Critical Assessment in China. Hum. Ecol. Risk Assess. Int. J. 2015, 21, 781-798. [CrossRef]

33. Zhao, J.; Zhou, N. Impact of Human Health on Economic Growth under the Constraint of Environment Pollution. Technol. Forecast. Soc. Chang. 2021, 169, 120828. [CrossRef] 
34. Conrad, E.; Cassar, L.F. Decoupling Economic Growth and Environmental Degradation: Reviewing Progress to Date in the Small Island State of Malta. Sustainability 2014, 6, 6729-6750. [CrossRef]

35. Song, T.; Wang, E.; Lu, X.; Chen, H.; Zhang, J. Research on the Calculation and Influencing Factors of the Green Development of Regional Industry in China. Reg. Econ. Dev. Res. 2020, 33-43. [CrossRef]

36. Walz, R. Competences for Green Development and Leapfrogging in Newly Industrializing Countries. Int Econ Econ Policy 2010, 7, 245-265. [CrossRef]

37. Jupesta, J.; Boer, R.; Parayil, G.; Harayama, Y.; Yarime, M.; de Oliveira, J.A.P.; Subramanian, S.M. Managing the Transition to Sustainability in an Emerging Economy: Evaluating Green Growth Policies in Indonesia. Environ. Innov. Soc. Transit. 2011, 1, 187-191. [CrossRef]

38. Grillitsch, M.; Hansen, T. Green Industry Development in Different Types of Regions. Eur. Plan. Stud. 2019, 27, 2163-2183. [CrossRef]

39. Morssy, A. Green Growth, Innovation and Sustainable Development. Int. J. Environ. Sustain. 2012, 1. [CrossRef]

40. Bailey, I.; Caprotti, F. The Green Economy: Functional Domains and Theoretical Directions of Enquiry. Environ. Plan. A: Econ. Space 2014, 46, 1797-1813. [CrossRef]

41. Pan, X.; Li, M.; Pu, C. Study on the industrial structure optimization under constraint of energy intensity. Energy Environ. 2021, 32, 134-151. [CrossRef]

42. Ning, G.; Zhao, J. The Empirical Analysis of China's Industrial Structure Optimization Based on Resources and Environment Constraints. In Proceedings of the 2016 International Conference on Education, Management, Computer and Society, Shenyang, China, 1-3 January 2016; pp. 976-979. [CrossRef]

43. Zhou, P.; Ang, B.W.; Wang, H. Energy and $\mathrm{CO}_{2}$ Emission Performance in Electricity Generation: A Non-Radial Directional Distance Function Approach. Eur. J. Oper. Res. 2012, 221, 625-635. [CrossRef]

44. Pastor, J.T.; Asmild, M.; Lovell, C.A.K. The Biennial Malmquist Productivity Change Index. Socio-Econ. Plan. Sci. 2011, 45, 10-15. [CrossRef] 